\title{
An American Aeroplane with Adjustable Wings
}

\author{
Improvements Necessary to Make Flying Safe, Practical and Commercial
}

By Carl Dienstbach

A DEvice by which the incidence of the wings to the line of the propeller thrust and the axis of the fuselage may be varied at will during tlight, strongly advocated by a writer in the Scientific American, and so bri liantly vindicated in France by the aeroplane "Pau Smith," was embodied still earlier in an American monoplane of the Blériot type, built by Ray Louis Matteson in California, and shown in the accompanying illustration.

A worm gear enables the angle of both wings to the fuselage to be changed simultaneously with a minimum of effort on the part of the pilot, and without disturbing the warping or the interaction between the two wings. The worm gear undoubtedly obviates two inherent difficulties of adjustable wings in providing an herent difficulties of adjustable wings in providing an easy action and, being non-reversible, automatically
locking the wings at any desired angle. Emergencies of flying, however, demand very quick action as well, and it must be possible to present the wings to the air at their steepest angle just an instant before touching the ground in landing, and this quite as suddenly as the grou in landing, and the quite as suddenly wis The wings must be swung with lightning speed into a
position where their drift largely exceeds their lift, and a slow change of their incidence by the hand of the pilot working a worm gear would result in the ver

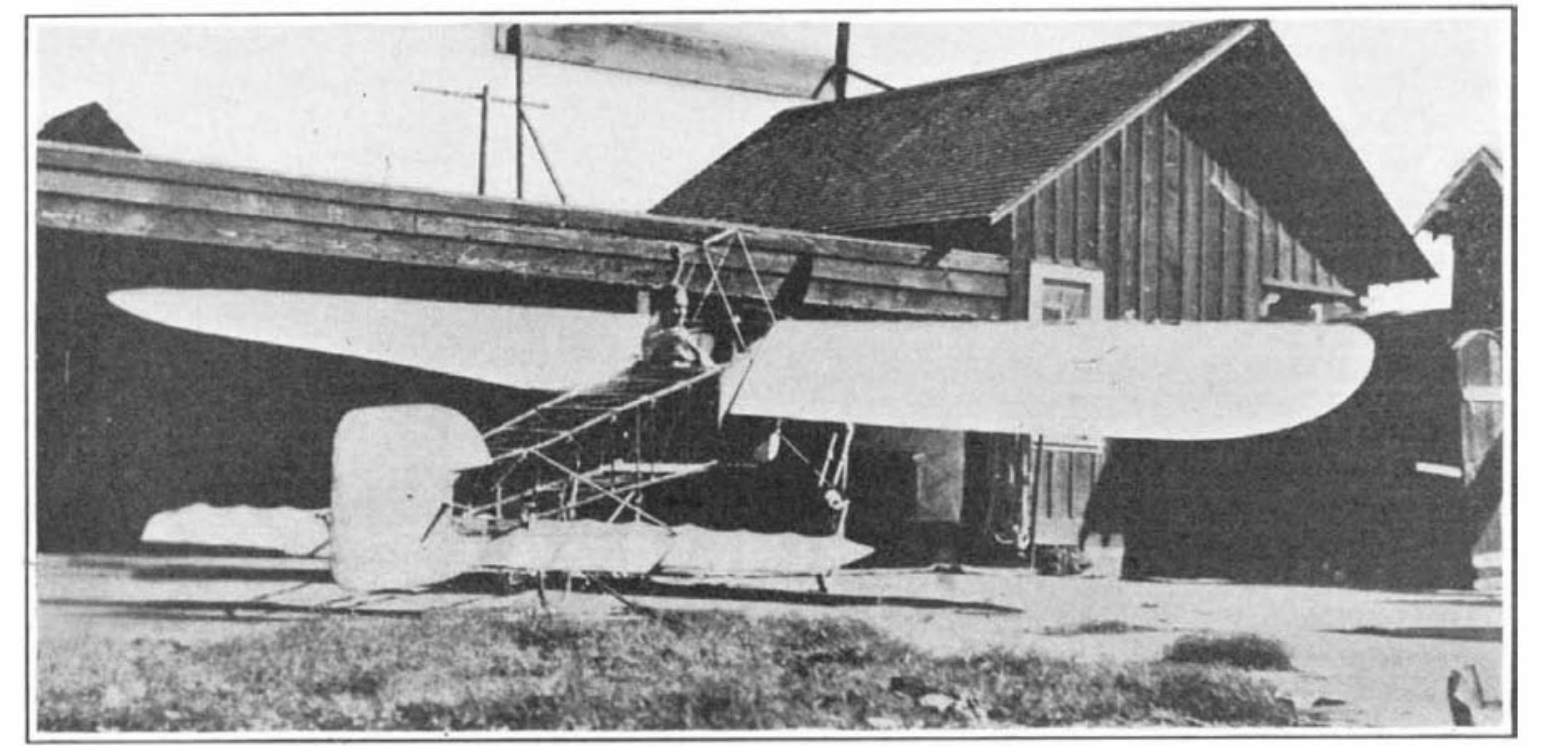

The Matteson adjustable wing monoplane.

opposite effect of sending the machine skyward. It is therefore necessary either to provide a clutch by which the motor may be made to drive the worm gear for an instant at a very high speed, and release it just a quickly, and an automatic band brake to stop just a suddenly any further movement; or the worm gear must be replace by a piston in a cylinder worked by compressed air from a tank, with suitable valve arrangements to instantly move it in either direction and lock it in any desired position. These mechanisms are so easy to provide that it would be a great pity if, first of all, an entirely novel and extremely useful way of laneing like a bird, practically without a subsequent run, could not be soon reduced to practice by an American machine.

The next task to be accomplished by an aeroplane with power adjustment of wing incidence would be to learn to practically stop in the air without falling, by shutting off power and "knocking" the wings into thei steepest angle and just as suddenly reduce that angle only a little and running the motor at maximum power. A really efficient execution of this maneuver calls indeed for a propeller whose pitch can be just as suddenly reduced to a maximum "standing pull"; and denly reduce to a maximum "standing pull"; and
eventually, even for a variable speed drive between eventually, even for a variable speed drive

motor and propeller, as in an automobile.
No doubt many designers would be horrified by such "complications." But we see to-day that the path of practical improvement for such a rough-and-ready machine as a motor bicycle does not tend in the direction of simplifying but of so-called complicating, by addin clutch and change speed drive. Ten years ago the automobile was crammed with complications and designer are now busy adding electric starters and adjustable carbureters, etc., to facilitate their operation. In the same manner, adding so-called complications opens the only way of making the primitive aeroplanes of to-da more reliable, more safe, and consequently, at last, more practical and commercial. Nature shows us in flying birds the most efficient, economical, and practical kind of locomotion-only the migrating plover can enjoy the fruits of Alaska. But the flying machinery of birds, with the possibility of an infinite number of adjustments, is a hundred times more complicated than the greater resourcefulness of mechanical àrts as compare to inherent limitations in biological development, the proposed aeroplane will share the great privilege of birds over all present flying. machines, in that they will not fall when an "airhole" suddenly destroys most of the relative motion between the air and the sustaining over them a wave of which aeroplanes are at present vainly trying to fen off by an inertia-forbidden sudden increase of speed The proposed machine will instantly increase its lift ight on the spot by a much steeper flying angle.

This of course calls for reserve power in the motor or rather increased size of an adjustable pitch propeller with "two-speed drive" from the motor, but is no less possible than a bird's sudden increase of lift, right on the spot, by the vigorous flapping of the whole wing. Lilienthal has shown that such flapping is economical in power, and in the case of the bird, similarly reduces
I oes all technical progress in flying have to dejent Instional tasks? Hirth predicted, also, high speed with small power; in other words, great radius of action for lightly loaded machines, due to refinement in design. If it was found necessary to equip the oceanflying "America" with a third motor, it does not look as though a prize for crossing the Atlantic would bring about this much desired progress.

The aeroplane closely resembles the bird in limitations, and a sea-going machine should "feed" from the water like a gull or an albatross. In the light of what has been said above, one word suffices in pointing to the possibility of easily resting and raising an "America" on and from troubled waters by enormous adjustable two-drive propellers and adjustable wings; in other words, developing great air lift at slow speed. The "America" fell back into the water after the hydroplanes had lifted her.

This would permit safe alighting, restarting, and picking up fuel from steamers. If a very small fraction of the weight saved in fuel were devoted to a powerful searchlight (weights of aerial lights have recently been greatly reduced), making dead reckoning from the water feasible at night; and if, during periods of fog, a modified patent log were dragged behind on a piano wire, with a predetermined breaking point, there would be no difficulty to rendezvous with steamers.

The parallel between the direct lifting-flapping of birds and an aeroplane with a steep angle of attack holds rood yet in another very important direction. In the last rejort of the Advisory Committee for the English government-now the most important contribution to the science publicly available, barring Eiffel's experiments-it was made clear that only with a high angle of attack is the aeroplane safe. from insidious air chutes, and that for this reason fast machines are, contrary to theories, always flown slower when pilots encounter treacherous air conditions, just as soaring gulls can be seen to resort to flapping in gusts.

Thus, what is proposed here means only the enlightened elaboration of a policy already tried and proven by the best authorities, with this difference, that it was not derive from blind practice only, but from extensive study.

A fast modern machine thus operated, with the sole help of the elevator, becomes a very crude apparatus, ill adapte to its new function. Part of the wing finds itself in a current descending from the propeller. The fuselage is forced broadside on through the air, making its streamline form useless ; and, worst of all, the small rudders and flaps, designed for normal speed, lose so much of their grip upon the air that they must be worked constantly near their critical angle, where further increase of effect becomes impossible, and the machine is in imminent danger of getting out of hand.

The small propeller designe for efficiency at high speed wastes as much power in slip as in starting, and the motor, even with throttle wide open, can no more run at maximum speed and power than in starting. run at maximum spee and power than in starting.
Wilbur Wright told the writer as early as 1905, with Wilbur Wright told the writer as early as 1905, with
his mystifying smile: "There is a propeller for everything, and the best propeller for normal flight is not the best propeller for starting." The obvious conclusion is that we need a propeller adjustable for different conditions. An yet, when a master designer like Chauvière exhibite it in large size, none seemed to grasp his purpose.

The proposed two-speed drive needs nothing like the range on an aeroplane that is require in a motorcycle. But when, with a maximum angle of attack for the wings, the greatest reduction of pitch for the enlarged propeller, which may be used without losing efficiency, propeller, whot allow the motor to run at maximum revodoes not yet allow the motor to run at maximum revo-
lutions, the advisability of shifting gears becomes oblutions, the advisability of shifting gears becomes ob-
vious. There are such simple, elementary, mechanical improvements needed in the present aeroplane that the constant expectations for something very far-fetched seem as pitiful as the wild fancies about the Wright machine while that was yet the famous mystery. The awarding of one of the two prizes given in the
recent safety contest in France to the "Paul Schmidt" recent safety contest in France to the "Paul Schmidt" was as just as that to its only successful rival who demonstrated so strikingly the beautiful mechanical brain now available for any type of flying machine, but improvement had not needlessly stopped short at adjustimprovement had not needlessly stopped short at adjust-
able wings, with Chauvière's adjustable propeller, ready able wings,

It must also be kept in mind that all these adjust- 
ments must be capable of being operated as quickly as a rudder is now swung to be available in emergencies and that Blériot's simple "bell" must be developed into something almost as complicated and yet as quick and easy to handle as the stops of an organ.

With this we return to the meritorious American "Bleriot" which furnished the occasion for this widescoped discussion. If, unlike the "Paul Schmidt," it has no record as yet of convincing tests, this is to be attribute to an error of the designer, who concentrate his efforts more on the attainment of automatic side control by a differential gear, automatically equalizing the pressure on self-adjusting warping wings. This would be possible if equilibrium could afford to neglect the direction of such pressures, but differences in direction of nearly 45 degrees may thus balance themselves in an extreme assumed case of a violent gust on the eft and lull on the right, and this leads ad absurdum the belief that equilibrium could be maintained in this manner.

\section{Pasteur's Words in Mankind's Struggle}

In view of the present conflict it may be well to recall Pasteur's words, spoken in 1888. They were as follows: "Two opposing laws seem to me to be now in contest. The one, a law of blood and death, opening out each day new modes of destruction, forces the nations to be always ready for battle. The other, a law of peace, work, and health, whose only aim is to deliver man from the calamities which beset him. The one seek ren sacrifices hundreds of thousands of lives to the ambition of a single individual. The law of which we (men of science) are the instruments strives, even through the carnage, to cure the wounds due to the law of war. Treatment by our antiseptic methods may preserve the Tres of thousands of soldiers. Which of these two laws will prevail, God only knows. But of this we may be ure, that science will obey the law of humaneness, an will always labor to enlarge the frontiers of life."

\section{A Home Made Electric Incubator and Brooder}

\section{A Safe, Simple and Efficient Device for the Home Mechanic}

By Charles B. Hayward

For the average "back-yard" chicken fancier, whose flock seldom es ceeds fifty fowls, an incubator is a superfluity. But at times the hen is exasperatingly fickle and refuses to assume the seclusion of maternal duties just at the time wh in her services as a hatching machine ar most in deman 1. An experience of this kind extending over two seasons, during which a small though very useful flock steadily diminished in numbers almost to the vanishing point, led to the construction of the incubato described here. There was no alternative but to buy chickens or to hatch them artificially, and as the latter was the more economical it was undertaken. However, the incubator problem was not one to be settled offhand, as the fire underwriters' rules prohibit the use of the lampheated type in insured buildings of any kind withou special permission, and this permission is difficult to obtain, except for the high-priced machines. Having no desire to hatch chickens $\dot{d} l a$ gentleman farmer at two to three dollars apiece, a high-priced incubator was out of the question. Moreover, the best lamp-heated types require more or less constant supervision, which is no desirable for the amateur whose only opportunity to look after such things is at the beginning and end of the day. As the "attach it to any socket" electrical device does not call for special inspection on the part of the fire underwriters, it was decided to build an electric incubator. Contrary to the general impression, there is nothing mysterious about an incubator. It is merely a heat-jroof box with provision for ventilation, heat-supply

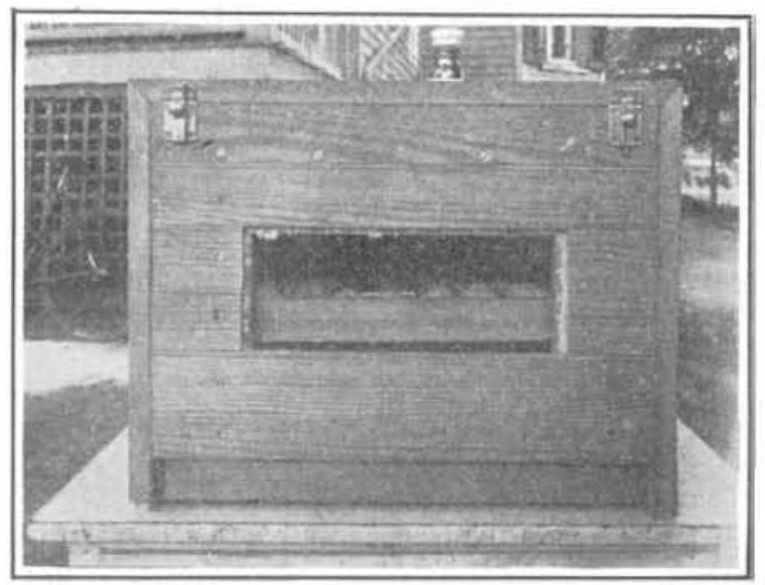

Complete incubator, closed, showing window and egg tray inside.

and the maintenance of the heat at a certain temperature -not lower than 100 deg. F. or higher than $105 \mathrm{deg}$. F. the mean sought for being $103 \mathrm{deg}$. F. at the upper surface of the eggs, to correspond to the temperature of the hen's body. Even less so is there any mystery about the electrical incubator; in fact, its construction and operation are simpler than the kerosene-heated type.

The following description should enable anyone who is at all handy with tools to readily duplicate the electric is at all handy with tools to readily duplicate the electric
incubator shown by the photographs. The cost of the materials complete is not quite five dollars, while a few evenings will suffice for its construction. The mode shown by the illustrations has done excellent work, so that for those who wish to duplicate it as it stands, it ct, it could have been smaller and still have served its purpose equally well. This refers more particularly to its height.

Matched pine ceiling 3-8 inch thick was used, being screwed to 1 by 2 -inch white pine framing, also screwed together. Screws were employed simply to avoid hammering; nails would de equally well though the screws made a stronger frume. This male a three-sided box, open at top, bottom and front, and with its frame plainly exposed inside. The space between the parts of the frame on each side was then filled with mineral wool and the frame covered with ceiling of the same kind as the outside, thus making a double-walled box with heatinsulating material in the walls. The front is of simila construction, except that it is hinged as a door and provided with a window, the details of its constructio being quite as evident upon inspection of the picture a a description could possibly make them. The same framing material is employed with cross pieces inserted in addition to make a frame for the window. A slight recess is chiseled out of the frame to permit the glass to rest flush with it and the ceiling is then fastened down

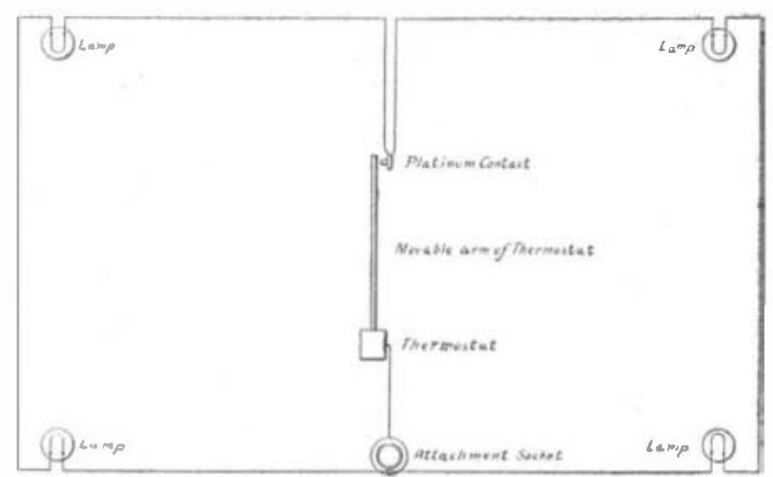

Diagram of wiring and thermostat.

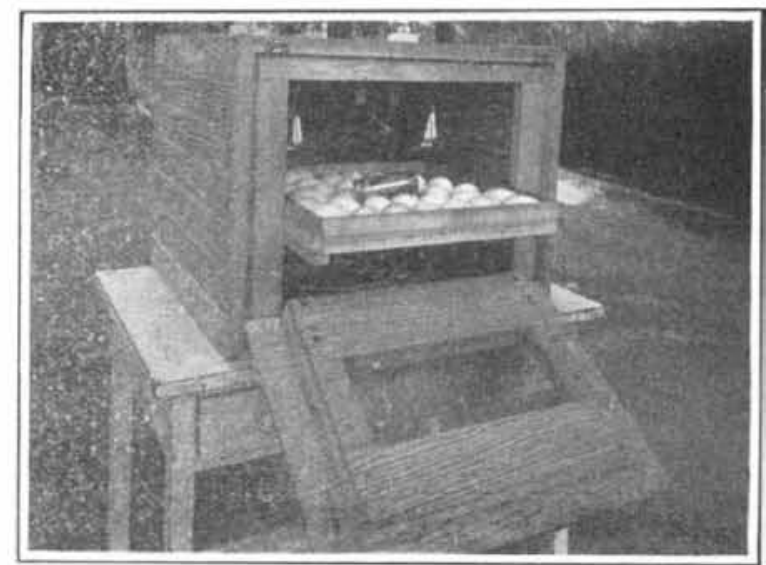

Interior and removable bottom. The dish is for water.

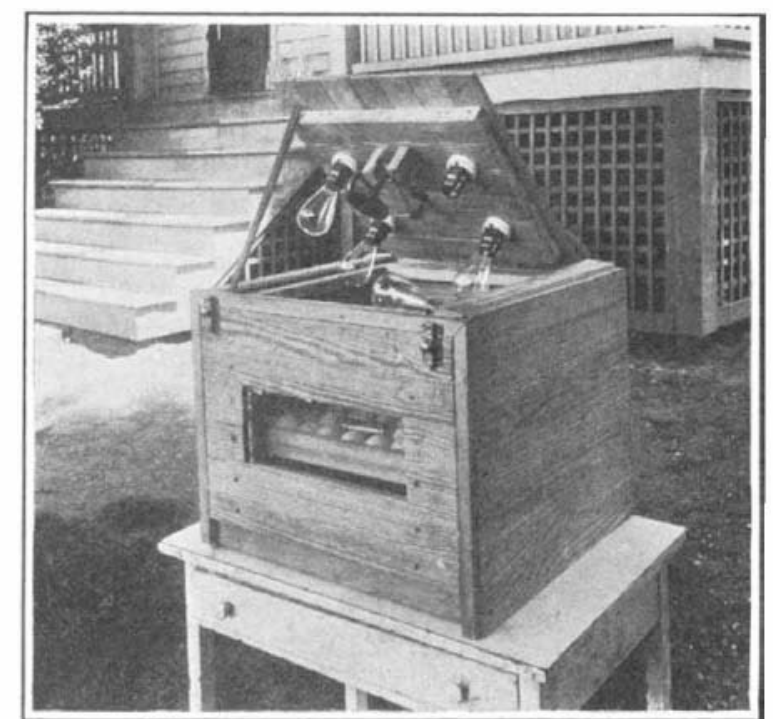

Details of heater and thermostat, one lamp removed to show contact over it, the remainder of the door having been filled with mineral wool. The glass is double to prevent heat loss. At a point about on a level with the lower edge of the window two strips of the 1 by 2 -inch framing are attached to the inner sides of the box to provide slides for the egg tray. This brings the eggs, thermometer and regulating device in plain view. The egg tray itself is made of $1 / 2$ by 2 -inch strips and 1/4-inch mesh galvanized wire netting. The bottom tray is also of the same construction and is made removable for cleaning as the new arrivals are placed on this to dry off during the course of the hatch.

The dimensions of the box are, height 17 inches, width and depth 22 inches. These are the outside dimensions, the inside being the same less the thickness of the walls. Through lack of foresight in planning the front construction it was necessary to make the egg tray somewhat smaller than would otherwise have been possible. As it stands it measures $151 / 2$ by 16 inches and has a capacity for between sixty and seventy hen eggs and forty to fifty duck eggs. This is ample for the amateur who keeps a small flock. The temptation to make or acquire a large incubator should be resisted as it must be borne in mind that hatching is only the first step, and unless given careful attention the mortality in a large flock of chicks will be high.

It will be apparent that this incubator could have been smaller without reducing its capacity, while a machine to hatch fifty eggs calls for a comparatively small box.

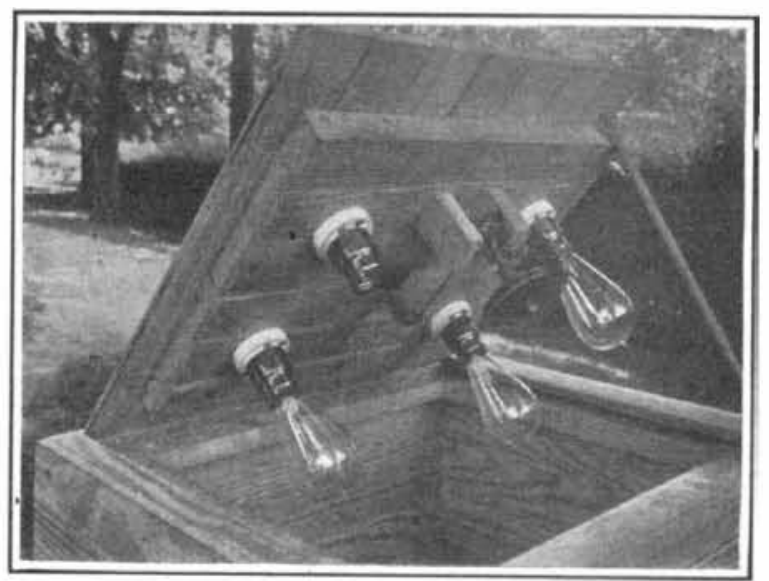

Detail of top connection of thermostat. One İamp removed to show contact.

"Hatch" in this connection is hardly correct. It should be maximum capacity, as there is always a substantial difference between the number of eggs put into the incubator and the number of chicks that hatch

The mechanical details of the top construction are quite apparent. This top is double and has the mineral wool insulation, except at the edges, where it is of a single thickness in order to fit flush. It is not fastened in place in order to permit of removal for access to the lamps and thermostat, though for that matter experience in the use of the model illustrated showed this to be unnecessary, as they could be reached equally well through the large door, while a permanently fastened top would be more efficient where heat insulation is concerned.

So much for the mechanical construction. The electrical end is equally simple. The actual heaters themselves are nothing more or less than 16 candle power carbon filament incandescent lamps, of which four are employed. These are wired in two groups, the two lamps in each group being in series with one another, both groups arrangement with relation to the latter will be plain upon reference to the wiring diagram shown. From one 